Article

\title{
Integration of Membrane Bioreactors with Edible Filamentous Fungi for Valorization of Expired Milk
}

\author{
Rahul Thunuguntla ${ }^{1}$, Amir Mahboubi ${ }^{1,2}{ }^{\mathbb{D}}$, Jorge A. Ferreira ${ }^{1, *}(\mathbb{D})$ and \\ Mohammad J. Taherzadeh ${ }^{1}$ (D) \\ 1 Swedish Centre for Resource Recovery, University of Borås, 50190 Borås, Sweden; \\ tvvumarahul@gmail.com (R.T.); amir.mahboubi_soufiani@hb.se (A.M.); \\ mohammad.taherzadeh@hb.se (M.J.T.) \\ 2 Flemish Institute for Technological Research, VITO NV, Boeretang 200, B-2400 Mol, Belgium \\ * Correspondence: jorge.ferreira@hb.se; Tel.: +46-33-435-4638
}

Received: 3 May 2018; Accepted: 6 June 2018; Published: 10 June 2018

check for updates

\begin{abstract}
Around 29 million tons of milk end as waste yearly in Europe, representing an environmental issue but also a potential substrate for biological valorization given its nutritional value. Aspergillus oryzae and Neurospora intermedia are edible filamentous fungi with dissimilar metabolism when grown in expired milk. Neurospora intermedia is more devoted to lactose consumption; 68 and $57 \%$ of lactose was consumed after cultivation in expired milk and its liquid fraction, respectively. Aspergillus oryzae consumed less lactose in expired milk (14\%), but led to better microfiltration characteristics of the final effluent due to fat and protein degradation. A two-stage fed-batch cultivation using membrane bioreactors (MBRs) was developed, bringing together both fungal metabolic characteristics when grown in $70 \%$ diluted expired milk. In the first MBR, A. oryzae degraded fat and protein, improved microfiltration, and produced ca $11 \mathrm{~g} / \mathrm{L}$ of biomass. In the second MBR, N. intermedia consumed the remaining lactose in the permeate and originated ca $7 \mathrm{~g} / \mathrm{L}$ of biomass. The developed system was successful for valorization of non-sterile milk due to the balance between consumption of bacterial growth-derived acids, consequent $\mathrm{pH}$, and fungal enzymatic activities. Besides, a final clear effluent ( $83 \%$ reduction of COD) was obtained, which is of interest considering wastewater treatment.
\end{abstract}

Keywords: ethanol; expired milk; edible filamentous fungi; fat degradation; fungal biomass; lactose consumption; membrane bioreactors; microfiltration; protein degradation; two-stage cultivation

\section{Introduction}

Increasing industrialization and population and better quality of life have the downfall of generating growing amounts of waste products. One example is milk, common in human diet. Around 830 million tons of milk were produced in 2017, a 1.4\% increase compared to 2016 [1]. However, after its expiring date, during production or transportation, milk ends as waste; only in Europe, around 29 million tons of dairy waste is produced yearly [2]. Research towards management of expired milk is scarce in the literature. Great emphasis has been given to the valorization of cheese whey [3-5] or to the life-cycle assessment of the dairy sector [6,7].

A vast fraction of valorization of waste products involves biological strategies, where microorganisms convert the nutrients in the medium to different value-added products. Filamentous fungi are crucial players in the development of a bio economy centered on production of green alternatives to fossil fuels and other products. Examples of products of fungal origin include antibiotics, human food, organic acids, enzymes, fuels and so forth [8,9]. It has been previously reported that the edible fungi Neurospora intermedia and Aspergillus oryzae can be applied for valorization 
of expired dairy products $[10,11]$. Both fungi are used to produce human food products including oncom and miso, respectively $[12,13]$. However, the growth of these fungi follows different metabolic routes. Neurospora intermedia has a preference for lactose assimilation and ethanol production while A. oryzae has a preference for fat degradation followed by lactose assimilation but no ethanol production $[10,11]$. This calls for an integrated strategy to attain full conversion of the nutrients in expired milk where the metabolic preferences of each fungus are favored. The use of membranes is common in a variety of separation and filtration applications. For instance, membranes are used for dairy wastewater purification [14]. Coupling membranes to bioreactors has opened a range of new potential applications. In the production of ethanol, membrane bioreactors (MBRs) allow in situ detoxification of lignocellulosic hydrolysates, cell retention and recycling, and enzyme separation and recycling [15]. Two configuration strategies are normally applied; namely immersed/submerged (iMBR) and side-stream/external loop (sMBR). The former is favored due to lower energy and space needed, and simple operation. In the iMBR, the negative pressure applied on the filtrate side defines the magnitude of the separation driving force and transmembrane pressure [16].

In this work, a two-stage fed-batch process using iMBRs integrated with A. oryzae and N. intermedia fungi was developed to achieve conversion of nutrients in expired milk to fungal biomass and ethanol, and release of glycerol during fat degradation. In the first stage, $A$. oryzae degrades mostly fat and proteins, thereby improving the microfiltration into the second iMBR, where $N$. intermedia consumes lactose. Reactor studies were preceded by shake-flasks experiments where the effect of sterilization time, milk fraction and dilution were investigated. To the best of our knowledge, the presented work is the first report on the integration of membrane bioreactors with edible filamentous fungi towards valorization of expired milk.

\section{Materials and Methods}

\subsection{Microorganisms}

The two ascomycete fungal strains Neurospora intermedia CBS 131.92, isolated from the peanut-based fermented food oncom, and Aspergillus oryzae CBS 819.72, isolated from tané koji used for sake making, were used throughout the research. Both fungi were acquired from Centraalbureau voor Schimmelcultures (Utrecht, the Netherlands). Maintenance of the fungus in potato dextrose agar medium and preparation of the spore solutions were carried out according to Ferreira, et al. [17].

\subsection{Dairy Substrate}

Milk containing 10\% solids (about 3\% fat, $4 \%$ sugars and 3\% protein) was used in this research. After purchase (ICA, Borås, Sweden), the product remained in a cold room at $5{ }^{\circ} \mathrm{C}$ and was used for experiments at day five after its expiring date ( $\mathrm{pH}$ 6.5); therefore, it is considered as expired milk.

\subsection{Shake-Flask Cultivations}

All cultivations were carried out in $250 \mathrm{~mL}$ narrow-necked E-flasks to which $100 \mathrm{~mL}$ of semi-synthetic or expired milk medium were added. Unless otherwise stated, all solutions were sterilized at $121{ }^{\circ} \mathrm{C}$ for $20 \mathrm{~min}$. All cultivations in semi-synthetic medium were carried out with $N$. intermedia, whereas both fungi were used during cultivations in expired milk. Twenty milliliters of spore solution $\left(4.9 \times 10^{6} \pm 8.4 \times 10^{5}\right.$ spores $\left./ \mathrm{mL}\right)$ per liter of medium were added to all flasks followed by incubation at $125 \mathrm{rpm}$ and $35^{\circ} \mathrm{C}$ in a water bath. Samples of $1.5 \mathrm{~mL}$ were withdrawn daily under sterilized conditions, centrifuged at $10,000 \times g$ and the supernatants stored in the freezer for further chromatographic analysis. All experiments were performed in duplicate.

\subsubsection{Cultivations in Semi-Synthetic Medium}

Semi-synthetic medium contained $50 \mathrm{~g} / \mathrm{L}$ of lactose, $5 \mathrm{~g} / \mathrm{L}$ of yeast extract and salts according to Sues, et al. [18]. Metal-containing solutions were sterilized separately and the final medium was 
adjusted before inoculation and maintained at $\mathrm{pH} 5.0$ throughout the cultivation. Carbon assimilation was studied by adding glycerol (10, 20 and $30 \mathrm{~g} / \mathrm{L})$, lactic acid (5, 10, 15 and $20 \mathrm{~g} / \mathrm{L})$, copper sulfate pentahydrate $(60 \mathrm{mg} / \mathrm{L})$, and trace metals according to Sues, et al. [18]; increasing yeast extract concentration to $11.6 \mathrm{~g} / \mathrm{L}$; varying the cultivation $\mathrm{pH}$ (4.0, 4.5 and 5.0); and inoculating the medium with biomass instead of spores. Adjustment of $\mathrm{pH}$ during cultivation was performed by adding $2 \mathrm{M}$ $\mathrm{H}_{2} \mathrm{SO}_{4}$ or $2 \mathrm{M} \mathrm{NaOH}$. Every $24 \mathrm{~h}$, two flasks were used for $\mathrm{pH}$ measurement and adjustment, and the amount needed to maintain the desired $\mathrm{pH}$ was added to the remaining cultivation samples.

\subsubsection{Cultivations in Expired Milk}

Single-microorganism cultivations with $N$. intermedia and $A$. oryzae were carried out in non- sterile milk (100 mL of medium were transferred to previously autoclaved Erlenmeyer flasks under sterile conditions) at $\mathrm{pH} 6.5$ and in sterile milk (for 5 and $20 \mathrm{~min}$ at $121^{\circ} \mathrm{C}$ ) at $\mathrm{pH} 4.5$ and 6.5. The $\mathrm{pH}$ was maintained during cultivation via addition of $2 \mathrm{M} \mathrm{H}_{2} \mathrm{SO}_{4}$ or $2 \mathrm{M} \mathrm{NaOH}$. Co-cultivations were also performed in sterile milk $\left(20 \mathrm{~min}\right.$ at $\left.121^{\circ} \mathrm{C}\right)$ at $\mathrm{pH} 4.5$ and 6.5. Single cultures with $A$. oryzae were also carried out in expired sterile milk containing 1 and $3 \mathrm{~g} / \mathrm{L}$ of $\mathrm{MgSO}_{4}$ at $\mathrm{pH} 6.5$ and 7.0. Further studies with $N$. intermedia included cultivations in separated liquid and solid fractions of expired milk (fraction separation was attained by centrifuging milk in $50 \mathrm{~mL}$ plastic tubes at $8000 \times g$ for 8 min followed by volume adjustment of the solid fraction with ultrapure water). The effect on substrate consumption by sterilization cooling time (sterilized fractions were taken out from the autoclave at 35 and $70^{\circ} \mathrm{C}$ ), and supplementation of the liquid fraction and solid fraction with $20 \mathrm{~g} / \mathrm{L}$ glycerol and $50 \mathrm{~g} / \mathrm{L}$ of lactose, respectively, was also studied. Single-microorganism experiments were also carried out in 50 and $70 \%$ diluted and sterilized expired milk. A two-stage cultivation was applied in 50 and $70 \%$ diluted expired sterile milk where a $72 \mathrm{~h}$ cultivation with $A$. oryzae was followed by a $72 \mathrm{~h}$ cultivation with $N$. intermedia. Using $70 \%$ expired sterile milk, inoculation with $N$. intermedia was carried out with or without pre-separation of $A$. oryzae biomass.

\subsection{Cultivation in Bench-Scale Airlift Membrane Bioreactors}

Fungal cultivations in milk were scaled up using 4.5-1 bench-scale airlift bioreactors transformed in membrane bioreactors by installing a $1 \mu \mathrm{m}$ pore size submerged membrane panel after removal of the internal loop tube. Cultivations were carried out in sterile $\left(20 \mathrm{~min}\right.$ at $\left.121^{\circ} \mathrm{C}\right)$ and non-sterile solid and liquid fractions as well as in 0,50 and $70 \%$ diluted non-sterile milk. All batch cultivations were carried out without $\mathrm{pH}$ adjustment (initial $\mathrm{pH}$ 6.5) using $3.5 \mathrm{~L}$ of milk, at $35^{\circ} \mathrm{C}$, and with an air flow of $2 \mathrm{~L} / \mathrm{min}$ supplied by the submerged membrane aeration lines. The membrane bioreactors were inoculated with $80 \mathrm{~mL}$ of spore solution $\left(4.9 \times 10^{6} \pm 8.4 \times 10^{5}\right.$ spores $\left./ \mathrm{mL}\right)$. A two-stage fed-batch cultivation in $70 \%$ diluted non-sterile milk was also carried by connecting the two airlift membrane bioreactors in series, where $A$. oryzae was inoculated in the first bioreactor and the filtered medium was added to a second bioreactor containing N. intermedia (Figure 1).

The membrane panel, composed of a semi-permeable 2nd generation integrate permeate channel (IPC) membrane, had a double filtration layer based on polyether sulfone (PES) (VITO NV, Mol, Belgium). The membrane panels had inbuilt two aeration lines at the right and left side corners that release air/gas through the bottom diffusers of $0.5 \mathrm{~mm}$ diameter each. Moreover, the membranes have one inner loop permeate line comprising the hollow area of very high porosity $(85 \%)$ within the intertwined fabric. The loop was used for the withdrawal of the filtrate/permeate. The membrane panel was cleaned before cultivation via treatment in a sterile beaker with sterile $2 \% \mathrm{NaOH}, 1 \% \mathrm{H}_{3} \mathrm{PO}_{4}$ and $200 \mathrm{ppm} \mathrm{NaOCl}$ solutions applied each for 20-30 min with an intermediary washing step with sterile water for $5 \mathrm{~min}$ at $45-50^{\circ} \mathrm{C}$. The cleaned membrane panels were then installed in the sterile airlift bioreactors. The scheme of the two-stage fed-batch process is presented in Figure 1. 


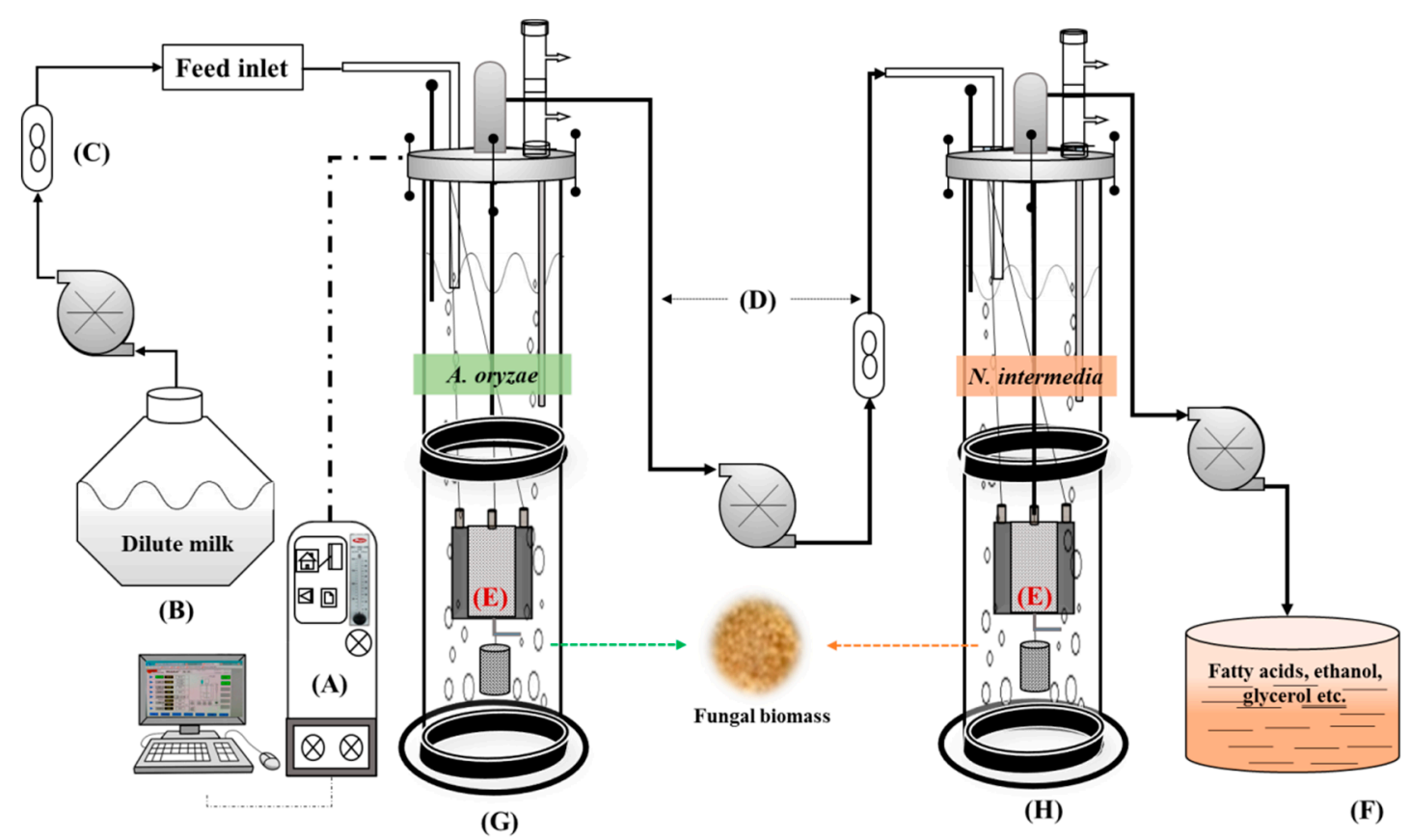

Figure 1. Scheme of the two-stage fed-batch cultivation in membrane bioreactors (MBRs) using both $N$. intermedia and A. oryzae filamentous fungi. A-Control unit; B-Feed tank; C-Flow meter; D-Permeate line; E-Membrane panels; F-Effluent; G-1st MBR (dilute milk + A. oryzae); H-2nd MBR (1st MBR permeate $+N$. intermedia).

\subsection{Analytical Methods}

Biomass dry weights per liter of medium were determined after oven-drying to constant weight at $70{ }^{\circ} \mathrm{C}$. A stainless-steel kitchen sieve (pore size $1 \mathrm{~mm}^{2}$ ) was used for the separation of solid-entangled biomass from the cultivated medium and the complex was thoroughly washed using distilled water before drying.

HPLC analysis of lactose, ethanol, glycerol, acetic acid, and lactic acid was carried out according to Ferreira, et al. [17]. The HPLC (Waters, Milford, MA, USA) had an ultraviolet (UV) absorbance detector operating at $210 \mathrm{~nm}$ in series with a Refractive index (RI) detector.

The total chemical oxygen demand (COD) of diluted milk and permeates of 1st and 2nd stages of double-stage MBR cultivation were measured using a NANOCOLOR 500 COD photometer (MACHEREY-NAGEL GmbH, Düren, Germany). Firstly, $0.2 \mathrm{~mL}$ sample was pipetted into the COD test tube and was vortexed. Then, tubes were heated using a NANOCOLOR heating block (MACHEREY-NAGEL GmbH, Germany) at $148{ }^{\circ} \mathrm{C}$ for $2 \mathrm{~h}$ and then vortexed and cooled for $30 \mathrm{~min}$. Finally, total COD was measured using the NANOCOLOR 500 D photometer.

\subsection{Statistical Analysis}

Statistical analysis was performed in Minitab ${ }^{\circledR} 17$ (Minitab Inc., State College, PA, USA). For that, ANOVA (analysis of variance) was applied using general linear models at a 95\% confidence interval together with pairwise comparisons according to Tukey's test; differences among results were regarded as significant at $p<0.05$. All standard error bars presented in the graphs throughout the text represent $\pm 2 \times \mathrm{SD}$ (standard deviation).

\section{Results and Discussion}

The present work led to the development of a strategy for conversion of nutrients in milk to various valuable products via a two-stage fed-batch cultivation with $N$. intermedia and A. oryzae in membrane bioreactors. During the first stage, $A$. oryzae degrades fat and protein producing biomass, 
thus easing medium filtration into a second membrane bioreactor, where $N$. intermedia converts the nutrients into additional biomass and ethanol. These products add to the released and unconsumed fatty acids, amino acids, and glycerol due to the hydrolysis reactions in the first bioreactor. Preliminary studies were conducted in both semi-synthetic medium and expired milk to gain insights in fungal growth for further reactor cultivation development.

\subsection{Cultivation in Semi-Synthetic Medium}

The fungus N. intermedia has been previously reported [19] to hydrolyze lactose and assimilate its degradation monomers glucose and galactose. Additionally, there are other nutrients in dairy waste, namely lactic acid, which is a product of bacterial metabolism, fat that releases glycerol and fatty acids when degraded, proteins, and minerals. Therefore, the influence of several factors, including glycerol and lactic acid concentration, $\mathrm{pH}$, and medium supplementation with copper sulphate, trace metals and yeast extract on the growth of $N$. intermedia were studied in semi-synthetic medium. Ultimately, a performance comparison was carried out between $N$. intermedia growth in semi-synthetic medium and expired milk. Glycerol was included to study the potential of using the biological conversion to both low- and high-fat dairy substrates and show the potentially wide application of the final developed strategy. Cultivations in semi-synthetic medium were carried out with only N. intermedia in view of the composition of the medium reaching the second bioreactor as part of the integrated strategy developed within this work. Understanding which conditions and substrate preference is of utmost importance in order to reach complete assimilation of nutrients in the second cultivation leading to a clear effluent easy to treat.

From single-carbon cultivations using glycerol at 10,20 , and $30 \mathrm{~g} / \mathrm{L}$ and lactose at $50 \mathrm{~g} / \mathrm{L}$, a similar consumption of glycerol of 7-8 g/L and $11 \mathrm{~g} / \mathrm{L}$ of lactose was obtained after $96 \mathrm{~h}$ of cultivation (Figure 2a). Consumption rates were $0.04-0.08$ and $0.09-0.012 \mathrm{~g} / \mathrm{L} / \mathrm{h}$ when the carbon source was glycerol or lactose, respectively. Finally, glycerol consumption and maximum consumption rates were not statistically different among the conditions tested here $(p=0.603)$. The biomass obtained $(4 \mathrm{~g} / \mathrm{L})$ was similar for all conditions studied. When both carbon sources were added to the semi-synthetic medium (lactose at $50 \mathrm{~g} / \mathrm{L}$ and glycerol at $20 \mathrm{~g} / \mathrm{L}$ ), N. intermedia consumed similar amounts (3-4 g/L) of both carbon sources. Substrate consumption maximum rates were significantly lower than those during single-carbon cultivations $(0.02-0.03(p=0.001)$ and $0.02-0.05 \mathrm{~g} / \mathrm{L} / \mathrm{h}(p=0.01)$ of glycerol and lactose, respectively).

When lactic acid (at 5, 10, 15 and $20 \mathrm{~g} / \mathrm{L}$ ) was added to the medium containing lactose and glycerol, carbon substrate consumption was inhibited at lactic acid concentrations above $10 \mathrm{~g} / \mathrm{L}$. A similar observation for lower lactic acid concentrations was that $N$. intermedia first depleted lactic acid before it started to consume lactose and glycerol, highlighting most probably the need of the fungus to relieve the inhibitory effect of the acid (Figure $2 \mathrm{~b}$ ). Only $1.3 \mathrm{~g} / \mathrm{L}$ of lactose and $3.1 \mathrm{~g} / \mathrm{L}$ of glycerol were consumed after 6 days of cultivation at $5 \mathrm{~g} / \mathrm{L}$ of lactic acid, whereas only $1 \mathrm{~g} / \mathrm{L}$ of glycerol was consumed when the acid was added at $10 \mathrm{~g} / \mathrm{L}$. Therefore, the results show that $N$. intermedia can grow in media containing $\leq 10 \mathrm{~g} / \mathrm{L}$ of lactic acid; however, longer lag phases are obtained.

In a further set of experiments, the addition of copper sulphate as a strategy to add the lactase cofactor, trace metals, or a higher amount of yeast extract did not lead to further statistically significant improvements in the assimilation of carbon sources $(p=0.227)$ (Figure $2 \mathrm{c}$ ). Controlling the $\mathrm{pH}$ during cultivation at 4.0, 4.5, and 5.0 did not lead to differences regarding carbon assimilation. On the other hand, inoculation of the medium with pre-grown biomass instead of spores significantly increased lactose consumption ( $18 \mathrm{vs}$. $5.5 \mathrm{~g} / \mathrm{L} ; p=0.030)$ and $N$. intermedia preference for lactose instead of glycerol became clearer (Figure $2 \mathrm{~d}$ ). Altogether, the components present in the semi-synthetic medium used in this study did not seem to support a satisfactory consumption of lactose; or when the disaccharide was present either as the sole carbon source or together with glycerol, suggesting the lack of key nutrients in the recipe. 


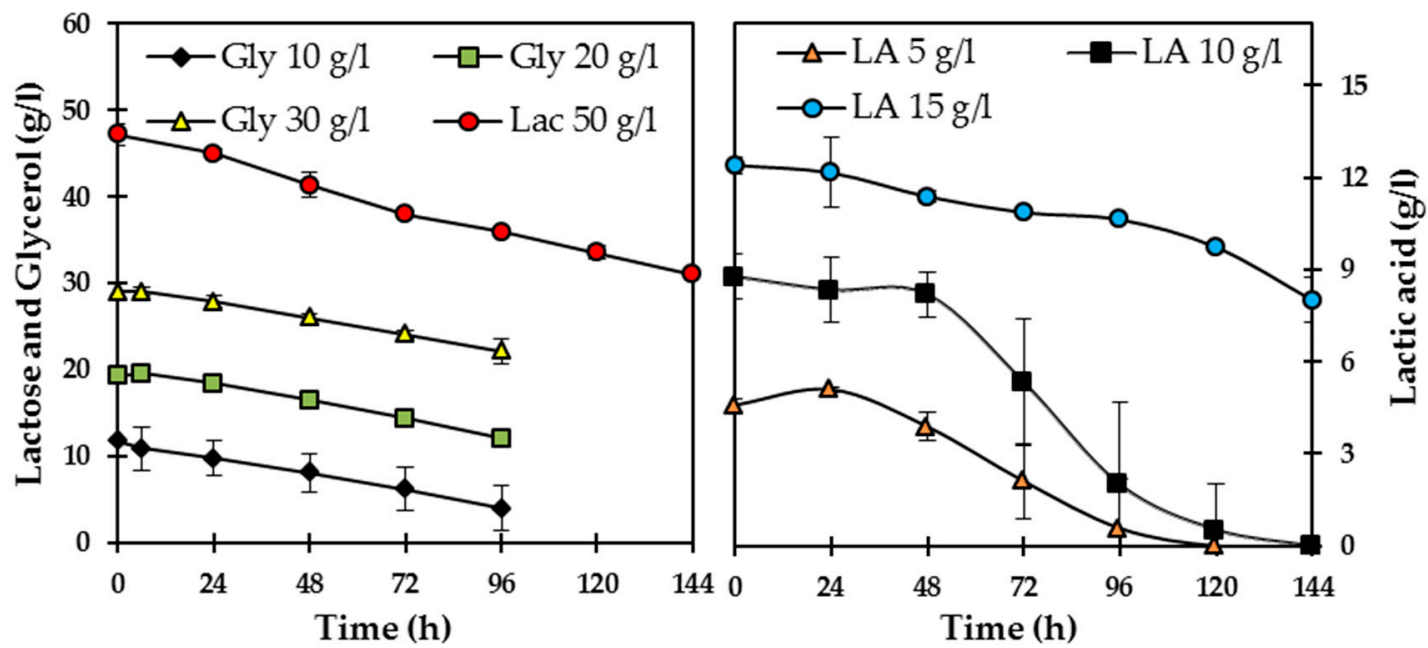

(a)

(b)

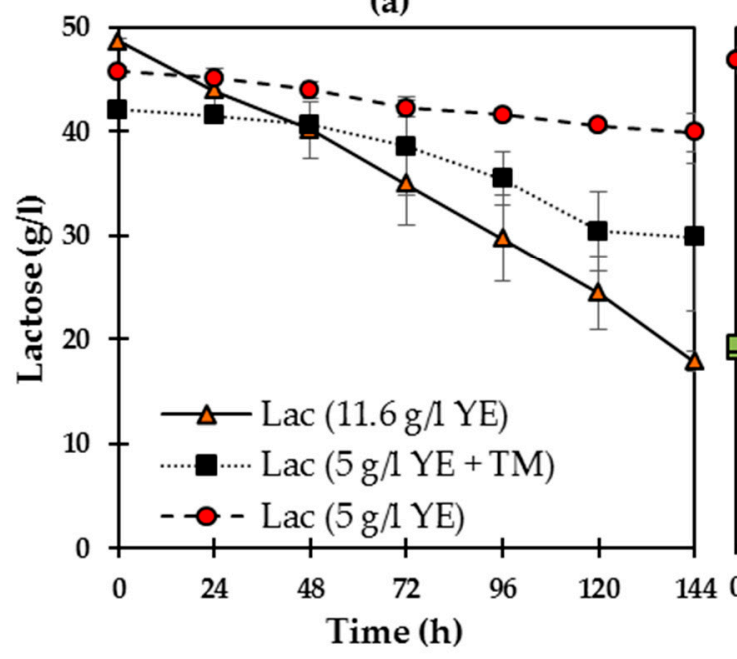

(c)

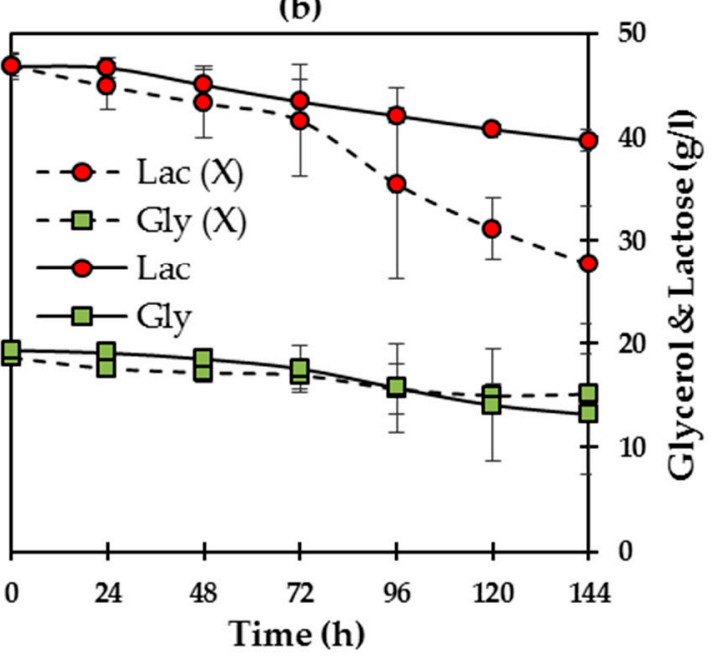

(d)

Figure 2. Lactose, glycerol, and lactic acid concentrations during cultivation of N. intermedia in semi-synthetic medium containing: (a) single-carbon glycerol and lactose; (b) glycerol, lactose, and lactic acid; (c) trace metals, yeast extract $(5 \mathrm{~g} / \mathrm{L})$, or a higher concentration of yeast extract (ca. $12 \mathrm{~g} / \mathrm{L})$; (d) glycerol and lactose where N. intermedia was added in the form of biomass instead of spores as it was the case for all other cultivations. Gly = Glycerol; Lac = Lactose; LA = Lactic acid; YE = Yeast extract; $\mathrm{TM}=$ Trace metals; $\mathrm{X}=$ biomass.

\subsection{Fungal Activity in Dairy Expired Medium}

\subsubsection{Effect of Sterilization, Sterilization Conditions and $\mathrm{pH}$ on Fungal Activity}

A preliminary screening has been performed in milk medium to test the metabolic activity of N. intermedia and A. oryzae in expired, sterilized (20 min at $121^{\circ} \mathrm{C}$ ) (Figure 3), and non-sterilized milk (results not included in Figure 3) at an initial $\mathrm{pH}$ of 6.5. Fungal growth was observed in all conditions. The consumption of lactose was higher in non-sterilized milk $(47 \mathrm{~g} / \mathrm{L})$ than in sterilized milk $(33 \mathrm{~g} / \mathrm{L})$; the fungal influence was lower in non-sterilized milk in comparison to sterilized milk. Such lower influence was likely to be triggered by a higher activity of lactic acid bacteria as up to $23 \mathrm{~g} / \mathrm{L}$ of the acid were produced. Moreover, a faster decrease in lactose concentration was observed after $48 \mathrm{~h}$ of cultivation, which coincided with the disappearance of the pellet morphology (obtained in non-sterile milk) of $A$. oryzae as well as with a concentration of lactic acid of $10 \mathrm{~g} / \mathrm{L}$. Moreover, there was a good correlation between the amount of lactic acid and decrease in fungal activity in non-sterile 
conditions, whereas a concentration higher than $10 \mathrm{~g} / \mathrm{L}$ was found to have a negative impact on fungal activity [20]. Such observations were in complete agreement with data obtained during experiments in semi-synthetic medium. The absence of sterilization led to high bacterial activity accompanied by higher lactose consumption and lactic acid production compared to when a sterilization step preceded the cultivation. It has been reported previously by Gerez, et al. [21] that the time of sterilization plays a significant role in the lactose assimilation by the fungi and fungal robustness towards bacteria.

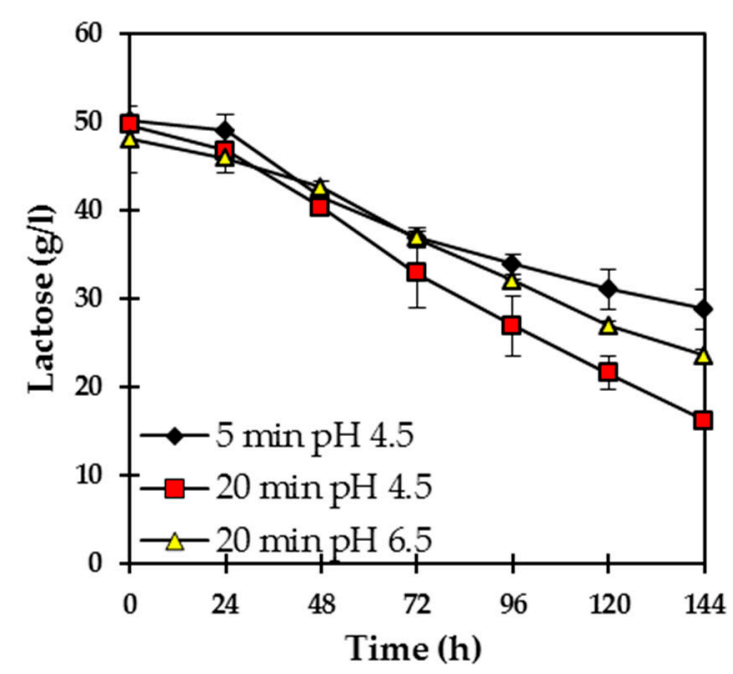

(a)

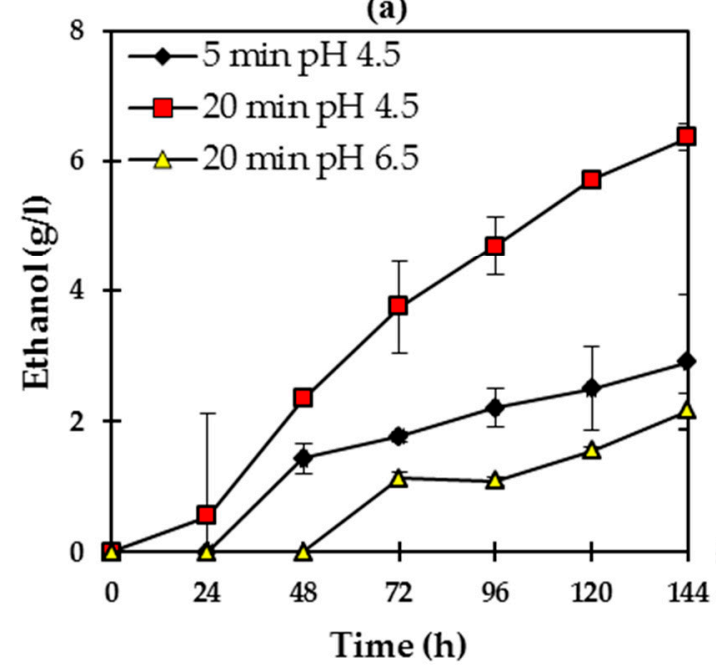

(c)

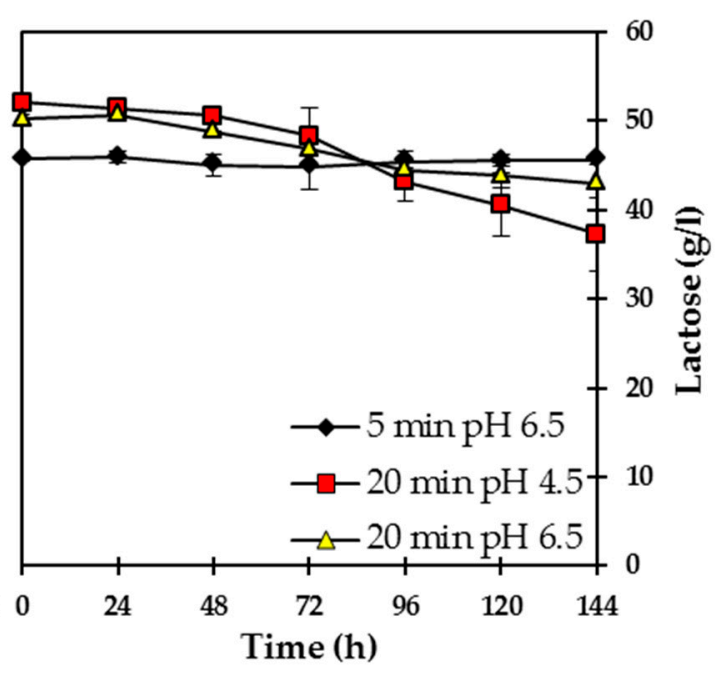

(b)

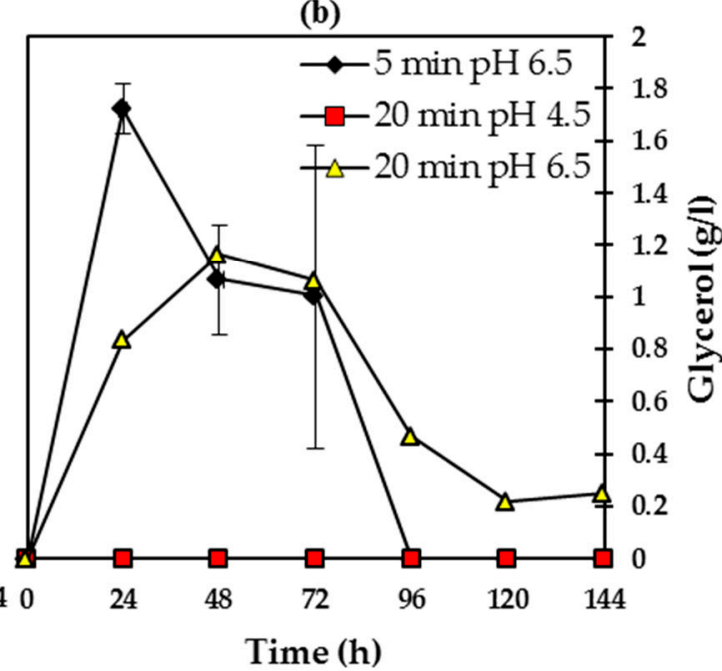

(d)

Figure 3. Profiles of lactose, ethanol, and glycerol during cultivation of $N$. intermedia $(\mathbf{a}, \mathbf{c})$ and A. oryzae (b,d) in milk sterilized for 5 and $20 \mathrm{~min}$ at initial $\mathrm{pH}$ of 4.5 and 6.5.

Single-microorganism cultivations were also carried in sterilized milk $\left(20 \mathrm{~min}\right.$ at $121{ }^{\circ} \mathrm{C}$, $\mathrm{pH}$ adjusted to 4.5). The $\mathrm{pH}$ of the medium had a significant impact on the fungal performance. As it can be observed in Figure 3a,c, higher lactose consumption ( 33 vs. $10 \mathrm{~g} / \mathrm{L}, p=0.018$ ) and ethanol production ( $6.5 \mathrm{vs} .2 .2 \mathrm{~g} / \mathrm{L} ; p=0.001$ ) were obtained when $N$. intermedia was cultivated at $\mathrm{pH} 4.5$ instead of $\mathrm{pH}$ 6.5. Similarly, A. oryzae consumed more lactose $(15 \mathrm{vs.} 7 \mathrm{~g} / \mathrm{L} ; p=0.034)$ during cultivation at $\mathrm{pH}$ 4.5 but produced less glycerol $(0$ vs. $1.2 \mathrm{~g} / \mathrm{L} ; p=0.007)$ compared to that formed during cultivation at the $\mathrm{pH} 6.5$ (Figure $3 \mathrm{~b}, \mathrm{~d}$ ). Altogether, $\mathrm{pH} 4.5$ favors lactose consumption by both strains and ethanol production by $\mathrm{N}$. intermedia, while $\mathrm{pH} 6.5$ favors fat degradation and glycerol release by A. oryzae. These results formed the basis for the integrated strategy developed in this work where $\mathrm{pH} 6.5$ was used in the first cultivation with $A$. oryzae and $\mathrm{pH} 4.5$ was the desired $\mathrm{pH}$ value for the second cultivation 
with $N$. intermedia. Therefore, these results proved that $N$. intermedia was clearly a better lactose consumer and ethanol producer than $A$. oryzae under the tested conditions ( $p=0.002$ for both groups of data). This is in accordance with previous studies where Mahboubi, et al. [10] and Klein, et al. [22] reported that $A$. oryzae had a higher tendency for fat degradation than to lactose assimilation.

The effect of sterilization time was also studied in this work (Figure 3). Neurospora intermedia and $A$. oryzae were individually cultivated in milk medium sterilized for $5 \mathrm{~min}$ at $121{ }^{\circ} \mathrm{C}$ and at an initial $\mathrm{pH}$ of 4.5 and 6.5, respectively. After a 5 min sterilization step, no bacterial activity was observed, as indicated by the absence of lactic acid production. Neurospora intermedia was found to be significantly more active in lactose consumption $(p=0.008)$ and ethanol production $(p=0.012)$ when grown in milk sterilized for $20 \mathrm{~min}$ ( 33 and $6.5 \mathrm{~g} / \mathrm{L}$, respectively) as compared to $5 \mathrm{~min}(21.5 \mathrm{~g} / \mathrm{L}$ and $3 \mathrm{~g} / \mathrm{L}$, respectively). The highest value of glycerol released $(1.7 \mathrm{~g} / \mathrm{L} ; p=0.017)$, while using A. oryzae, was obtained during cultivation in milk sterilized for $5 \mathrm{~min}$. The obtained results have proven that a short sterilization time ( $5 \mathrm{~min}$ ) is enough to avoid bacterial activity, but it is not the best condition to achieve the highest fungal growth performance considering lactose consumption and ethanol production by $N$. intermedia. When testing the addition of magnesium, no differences were found regarding release of glycerol by $A$. oryzae. Studies in literature have shown the positive effect of magnesium on lipase activity though $[23,24]$.

Co-cultivations were also carried out in 20 min sterilized milk at initial pH 4.5 and 6.5 (data not shown graphically). Lactose consumption was significantly lower $(p=0.000)$ in both situations than the maximum obtained at $\mathrm{pH} 4.5$ by $\mathrm{N}$. intermedia $(12.6 \mathrm{~g} / \mathrm{L}$ and $22 \mathrm{~g} / \mathrm{L}$ of lactose were consumed at initial $\mathrm{pH}$ of 6.5 and 4.5 , respectively). However, it was significantly higher than that in single-fungal cultivation with $A$. oryzae ( $p=0.0038-0.004)$. A similar maximum of glycerol (ca $2 \mathrm{~g} / \mathrm{L}$ ) was formed in both tested conditions, but no ethanol was produced at initial $\mathrm{pH}$ of 6.5 and a lower amount $(2 \mathrm{~g} / \mathrm{L})$ was obtained at the initial $\mathrm{pH}$ of 4.5 .

\subsubsection{Effect of Milk Fractions}

Milk was separated into its liquid and solid fractions for cultivation of N. intermedia at pH 4.5. The solid fraction was supplemented with lactose. As it can be observed in Figure $4 \mathrm{a}$, nutrients present in the liquid fraction give the highest contribution to consumption of lactose; at the end of the cultivation, around $29 \mathrm{~g} / \mathrm{L}$ of lactose had been consumed in the liquid fraction in comparison to $8 \mathrm{~g} / \mathrm{L}$ when the ascomycete was grown in the solid fraction supplemented with lactose. Furthermore, higher biomass ( 29 vs. $1 \mathrm{~g} / \mathrm{L}$ ) and ethanol $(6$ vs. $0 \mathrm{~g} / \mathrm{L})$ production was obtained during cultivation in the liquid fraction. Altogether, milk is a more suitable growth medium compared to semi-synthetic medium for $N$. intermedia with respect to lactose consumption $(p=0.023$ taking into consideration the highest amount of lactose consumed in semi-synthetic medium $(18 \mathrm{~g} / \mathrm{L}))$.

The effect of sterilization cooling time on lactose assimilation in liquid fraction of milk was also studied (Figure 4 b). Higher lactose consumption ( 33 vs. $14 \mathrm{~g} / \mathrm{L} ; p=0.005)$ and ethanol ( $6 \mathrm{vs.} 3 \mathrm{~g} / \mathrm{L}$; $p=0.008)$ production were observed when the medium was taken out from the autoclave at $70{ }^{\circ} \mathrm{C}$ instead of letting it slowly cooling down to $35^{\circ} \mathrm{C}$. The higher performance of the fungus in the medium taken out at $70{ }^{\circ} \mathrm{C}$ might be related to higher dissolution of proteins, whereas higher precipitation takes place when allowing the medium to slowly cool down to $35^{\circ} \mathrm{C}$. Neurospora intermedia was also cultivated in the liquid fraction of milk supplemented with $20 \mathrm{~g} / \mathrm{L}$ of glycerol. A similar consumption of lactose $(21 \mathrm{~g} / \mathrm{L})$ and glycerol $(18 \mathrm{~g} / \mathrm{L})$ was obtained during cultivation (Figure $4 \mathrm{c})$. Therefore, the total consumption $(39 \mathrm{~g} / \mathrm{L})$ was significantly higher than that achieved $(29 \mathrm{~g} / \mathrm{L})$ when only lactose was present in the medium $(p=0.010)$. Similar trends were observed during cultivation in semi-synthetic medium containing both carbon sources. The amount of biomass produced was found to be significantly lower in the liquid fraction supplemented with glycerol compared to the medium without supplementation ( 13 vs. $29 \mathrm{~g} / \mathrm{L} ; p=0.038$ ). Therefore, glycerol supplementation had an impact on lactose assimilation and biomass production. 


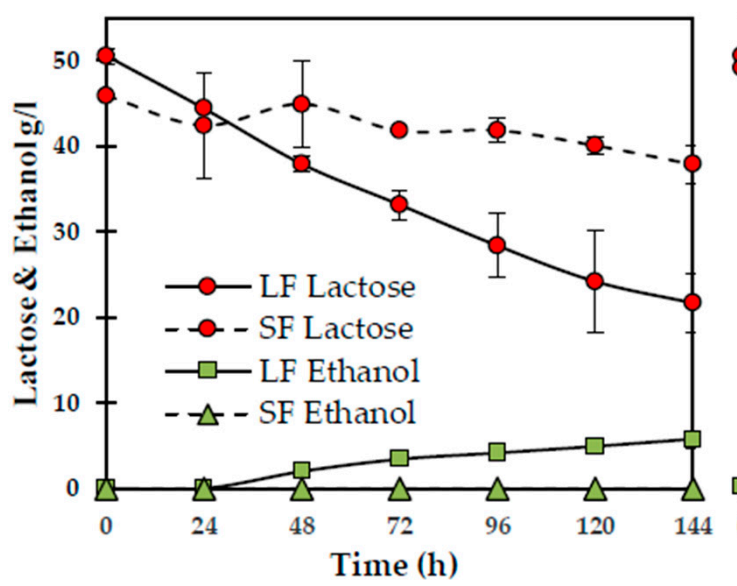

(a)

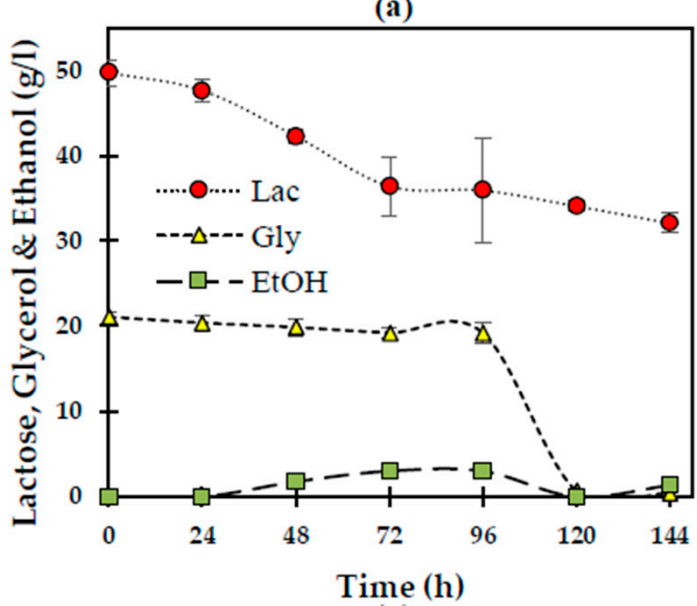

(c)

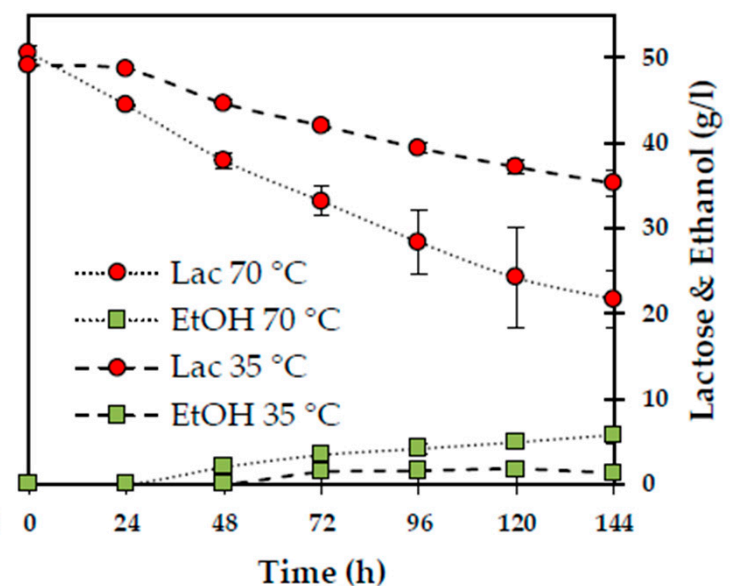

(b)

Figure 4. Profiles of lactose, ethanol and glycerol during cultivation of $N$. intermedia in liquid and solid fraction of milk: (a) liquid fraction after centrifugation, and the remaining solid fraction mixed with ultrapure water and supplemented with lactose; (b) liquid fraction of milk where the cooling temperature at which the samples were removed from the autoclave was of 35 and $70{ }^{\circ} \mathrm{C}$; (c) liquid fraction of milk supplemented with glycerol.

\subsubsection{Effect of Milk Dilution and Two-Stage Cultivation Strategy}

The effect of milk dilution on fungal activity in expired milk was studied using single-microorganism culture and a two-stage cultivation strategy (Figure 5). When A. oryzae and N. intermedia were cultivated separately in 50\% and 70\% diluted sterilized milk (Figure 5a), similar lactose consumptions (9-10 and 11-13 g/L, respectively) were obtained. Three observations were common to both conditions: a much lower biomass $(4 \mathrm{~g} / \mathrm{L})$ was obtained for $N$. intermedia as compared to cultivation with $A$. oryzae $(16 \mathrm{~g} / \mathrm{L})$ (such biomass differences were related to the complex between $A$. oryzae biomass and the medium components); the cultivation with $A$. oryzae gave rise to a clear liquid after biomass/solids harvesting; and no ethanol production was observed in any of the tested conditions. Glycerol production $(1.3 \mathrm{~g} / \mathrm{L})$ was observed only during cultivation of $A$. oryzae in $50 \%$ diluted milk. 


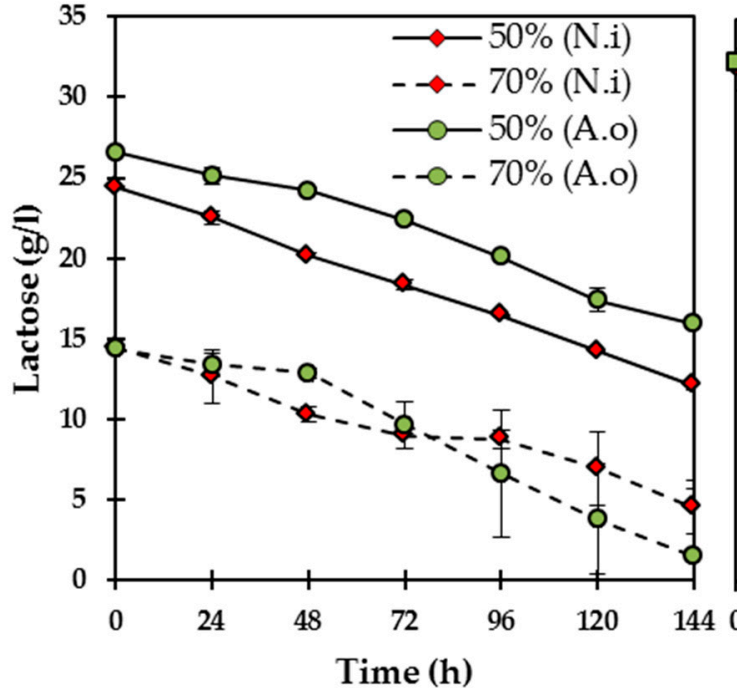

(a)

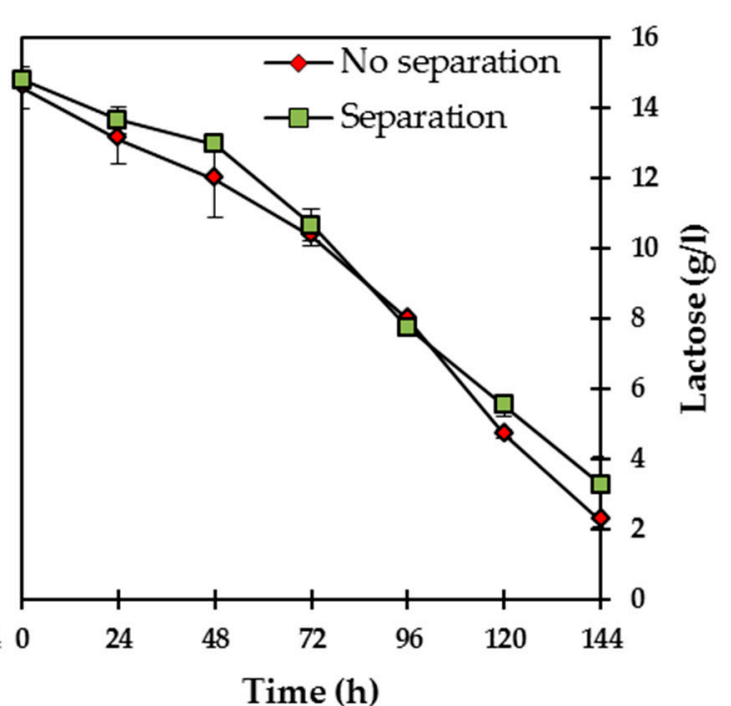

(b)

Figure 5. Profiles of lactose during single-microorganism cultivation in 50 and 70\% diluted milk (a) and co-culture cultivation in $70 \%$ diluted milk (b).

A two-stage cultivation was applied to $0,50,70 \%$ diluted milk, where $A$. oryzae was grown in a first stage during $72 \mathrm{~h}$, followed by inoculation with $N$. intermedia and a second cultivation stage lasting another $72 \mathrm{~h}$. According to the statistical analysis, the final lactose consumption was similar at 0 and $70 \%$ diluted medium, but significantly lower than that at $50 \%$, even though $p(0.044)$ is very close to the limit (0.05). However, since during experiments at reactor scale, foaming problems were observed when using pure milk and membrane fouling was observed during filtration tests of $50 \%$ diluted milk, $70 \%$ was the chosen concentration for further shake-flasks experiments. Using $70 \%$ diluted medium, the two-stage cultivation was also studied with separation of $A$. oryzae biomass before $N$. intermedia inoculation, which did not affect the final lactose consumption $(p=0.130)$ (Figure $5 b)$. Glycerol production of $0.4-0.5 \mathrm{~g} / \mathrm{L}$ was observed in both situations, whereas ethanol production $(0.5 \mathrm{~g} / \mathrm{L})$ was only observed when $A$. oryzae biomass was not removed before inoculation with $N$. intermedia.

\subsection{MBR Fungal Cultivation in Sterile and Non-Sterile Milk Medium}

Considering the results of shake flask fungal cultivations in sterile (S-) and non-sterile (NS-) milk and its fractions, MBR cultivations were performed to evaluate the filtration performance and the compatibility of the results in larger scale. In order to have an understanding of the filtration behavior of milk using synthetic polymer membrane, initially $850 \mathrm{~mL}$ of 2- and 10- times diluted NS-whole milk were subjected to filtration using 0.3 and $1 \mu \mathrm{m}$ pore sizes PES IPC membrane. It was observed that, as expected due to the complex lipid and protein content of milk [25], the membrane surface totally fouled in both media (figure not presented). As reported in the literature, this filtration failure in milk media is mainly due to the presence of lipids $[25,26]$. This deterioration in filtration performance was demonstrated by the sharp drop in the permeate flow. The best filtration performance was obtained for the 10-times diluted sample, with an average $13 \mathrm{~mL} / \mathrm{h}$ permeate withdrawal, running for $3 \mathrm{~h}$ before complete fouling.

It has previously been reported that the fungal strains A. oryzae and N. intermedia applied in this research work are capable of secreting a variety of enzymes such as lactases for lactose hydrolysis and assimilation, and proteases and lipases that assist denaturation and degradation of protein and fat components of dairy products, respectively $[10,27]$. Therefore, in order to examine fungal utilization of nutrients to facilitate membrane filtration of the products, bioreactor cultivations of $N$. intermedia in lactose-rich (liquid supernatant after centrifugation) and A. oryzae in protein- and lipid-rich fractions of milk were performed. The protein- and lipid-rich fractions of milk consisted of the remaining 
solids after centrifugation of milk containing fat and thermally denaturized proteins. As N. intermedia was cultivated in the liquid fraction of milk, similar lactose assimilation compared to that of shake flask cultivation was obtained for both S- $(20 \mathrm{~g} / \mathrm{L})$ and NS-media $(29 \mathrm{~g} / \mathrm{L})$. Moreover, after $120 \mathrm{~h}$ of cultivation, the initially turbid liquid fraction had turned into a clear medium containing suspended fungal biomass. Due to the presence of lactic acid bacteria (LAB) in the NS-fraction, $8 \mathrm{~g} / \mathrm{L}$ of lactic acid were built up in the medium from 48 to $72 \mathrm{~h}$ (Figure 6a). Not only did the presence of this level of lactic acid in the media not disturb fungal activity, but $N$. intermedia was even capable of utilizing and reducing the acid level until $120 \mathrm{~h}$. Production of nearly $3 \mathrm{~g} / \mathrm{L}$ ethanol was observed in the NS-cultivation, which could be attributed to the activity of the heterofermentative LAB [28] and/or $N$. intermedia due to the favorable low $\mathrm{pH}$ as the result of lactic acid production [10].

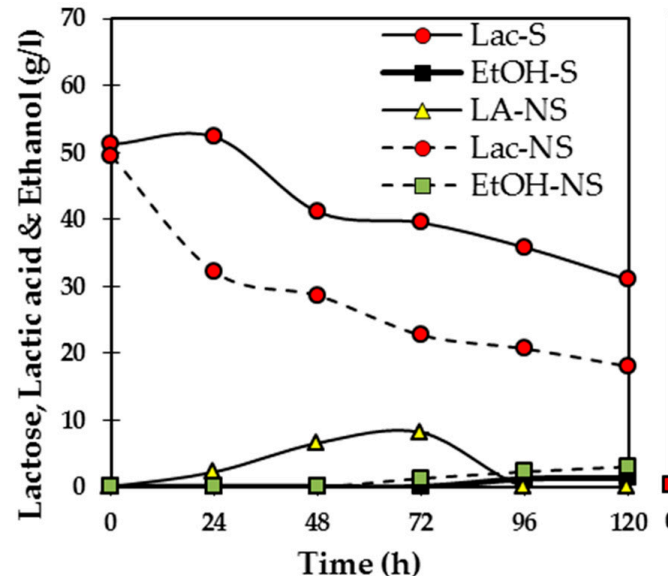

(a)
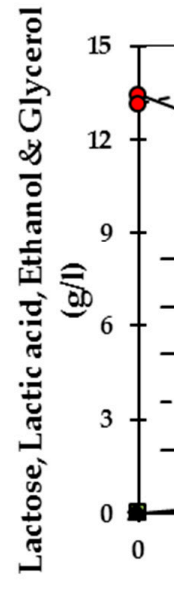

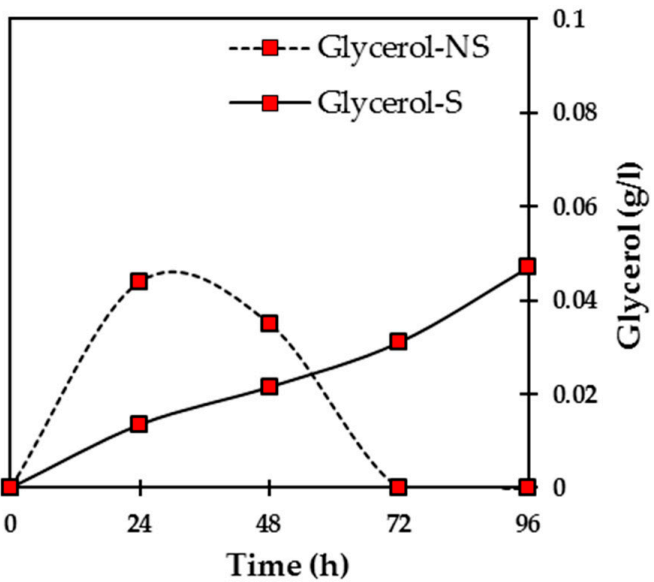

(b)

Figure 6. Changes in the concentrations of substrate and metabolites during cultivation of: (a) N. intermedia in liquid fraction; (b) A. oryzae in solid fraction of sterile (-S) and non-sterile (-NS) milk; (c) Lactose assimilation and ethanol and glycerol production by $N$. intermedia and A. oryzae in $70 \%$ diluted milk medium.

The same approach was taken in cultivation of $A$. oryzae in the solid fraction of milk. In parallel, the same S- and NS-media were used for shake flask fungal cultivation. The glycerol released in both conditions, due to fat degradation, was ca 0.04-0.05 g/L (Figure 6b). Aspergillus oryzae can degrade high contents of dairy lipid to glycerol and fatty acids in fat-rich dairy media [11]. However, regarding the physical characteristics of the media, it was observed that about $8 \mathrm{~g} / \mathrm{L}$ of biomass was produced after $120 \mathrm{~h}$ of cultivation in S- and NS-media, and a clear and transparent liquid remained in both cases. 
As the main goal of this research work was to treat whole milk using an MBR to have an integrated process with reduced processing stages benefiting from the different metabolic activities of the two fungal strains, MBR cultivation of both fungal strains in whole milk was investigated. In this regard, fungi were cultivated in whole milk in batch mode for $72 \mathrm{~h}$ prior to the start of filtration. However, due to excessive casein denaturation and separation, severe foam formation as the result of aeration and casein build-up on the reactor head space, and also considerable membrane fouling, filtration could not be preceded effectively.

In order to alleviate the issues related to excessive foaming and casein separation, remediate membrane fouling and ease of the filtration of the medium, and to reduce the conversion time needed for fungal treatment, milk samples were diluted using sterile milli-Q water. The whole milk was diluted up to $\sim 70 \%$ based on the aforementioned filtration results of the diluted milk with no acting microorganism. Fungal strains of A. oryzae and N. intermedia were cultivated in separate MBRs for a period of $120 \mathrm{~h}$ (Figure 6c). In accordance to the earlier made membrane filtration experiments, after $72 \mathrm{~h}$, both media were subjected to filtration for the removal of fungal metabolites while retaining the fungal mycelia in the reactor. In order to keep the liquid level constant, permeate obtained through filtration was recirculated back to the media. It was observed that although the treated medium with A. oryzae could easily be filtrated without any substantial membrane fouling and reduction in permeate flux (stable at $6.12 \mathrm{~mL} / \mathrm{h} . \mathrm{cm}^{2}$ ) for several hours, the medium used for cultivation of $N$. intermedia fouled the membrane in early stages of filtration (flux dropped to $0.26 \mathrm{~mL} / \mathrm{h} . \mathrm{cm}^{2}$ ). This $96 \%$ difference in filterability of the same media inoculated with different fungal strain proves that, unlike N. intermedia, A. oryzae has been capable of degrading and/or consuming milk lipids and proteins that were previously problematic regarding membrane fouling. The final biomass obtained from cultivation N. intermedia $(6 \mathrm{~g} / \mathrm{L})$ in this condition was nearly half of that of $A$. oryzae $(11 \mathrm{~g} / \mathrm{L})$. However, $N$. intermedia proved to be a better strain in controlling the cultivation conditions by utilizing lactic acid resulting from bacterial activity and controlling the $\mathrm{pH}$. As the $\mathrm{pH}$ in the preparation with $N$. intermedia dropped from 6.3 to about 5.4 throughout $144 \mathrm{~h}$ cultivation, that of $A$. oryzae was substantially lower $(\mathrm{pH}=4.3)$. Therefore, in order to have full conversion of milk nutrient by fungal activity using a stepwise treatment with $A$. oryzae prior to cultivation of $N$. intermedia for lactose removal in an MBR is essential. As it is illustrated in Figure $6 \mathrm{c}$ and as it has been corroborated in shake flask scale experiments, $N$. intermedia more successfully assimilates lactose reaching $64 \%$ consumption of its initial concentration in comparison to $27 \%$ by $A$. oryzae after $120 \mathrm{~h}$. Although the initial fat content of the diluted milk media was low $(9 \mathrm{~g} / \mathrm{L})$, the release of $0.3 \mathrm{~g} / \mathrm{L}$ of glycerol during A. oryzae $(48 \mathrm{~h})$ cultivation dominates fat degradation. The glycerol released was later consumed by the fungal strain. Moreover, during cultivation of A. oryzae, after $12 \mathrm{~h}$ of cultivation, casein content of the medium totally coagulated most probably due to the secretion of aspartic proteases by the fungal strain $[27,29]$. However, this separated casein was further dispersed as suspended particles by $72 \mathrm{~h}$ of cultivation.

Based on the acquired results, in order to build up a robust fungal bioconversion of expired milk into value-added products and to reduce the COD of the treatment effluent, a double-stage iMBR was developed. As presented in Figure 1, the double-stage MBR included an iMBR for cultivation of $A$. oryzae in diluted milk, a buffer tank, and a second iMBR for cultivation of $N$. intermedia in the permeate from the first reactor. The interconnected MBR system was set in a semi-continuous mode. A. oryzae was cultivated in the first MBR containing 3.51 of diluted milk for $72 \mathrm{~h}$ followed by filtration and removal of 11 of the medium to the connected buffer tank. This 11 was replaced by fresh milk medium. After $48 \mathrm{~h}$ of cultivation the second filtration cycle, another 11 was withdrawn and fed to the tank. The second MBR was then fed with the 21 permeate (starting volume) and inoculated with $N$. intermedia. From this stage onwards, every $72 \mathrm{~h}, 0.51$ of the medium in the second MBR was removed and directly replaced by 0.51 of permeate from $48 \mathrm{~h}$ treated medium from the first MBR.

The changes in the concentration of different compounds during cultivation of $A$. oryzae in semi-continuous mode with periodical filtration and feeding are presented in Figure 7a. During the start-up phase, prior to filtration, $41 \%$ of the initial lactose content of the medium was converted to 
biomass and metabolites by $A$. oryzae. This lactose consumption in between every feeding interval was around $50 \%$ during $48 \mathrm{~h}$. This better lactose consumption of $A$. oryzae in the MBR compared to shake flask cultivations could be due to better fungal growth condition in the highly aerated reactor. Although the production of lactic acid as a result of LAB activity was not detected in the 1st stage MBR, bacteria are likely to be present in the non-sterile milk medium; acetic acid producing bacteria actively produced the acid from $72 \mathrm{~h}$ to the end of the cultivation $(4.2 \mathrm{~g} / \mathrm{L})$. The semi-continuous iMBR cultivation proved to be satisfyingly robust in $\mathrm{pH}$ control, not to be dramatically affected by the changes in the acetic acid content of the medium, as the filtration and feeding regime plus metabolic activity of A. oryzae could sustain the $\mathrm{pH}$ of the medium within 4.6-6.4 throughout the cultivation (Figure 7a).

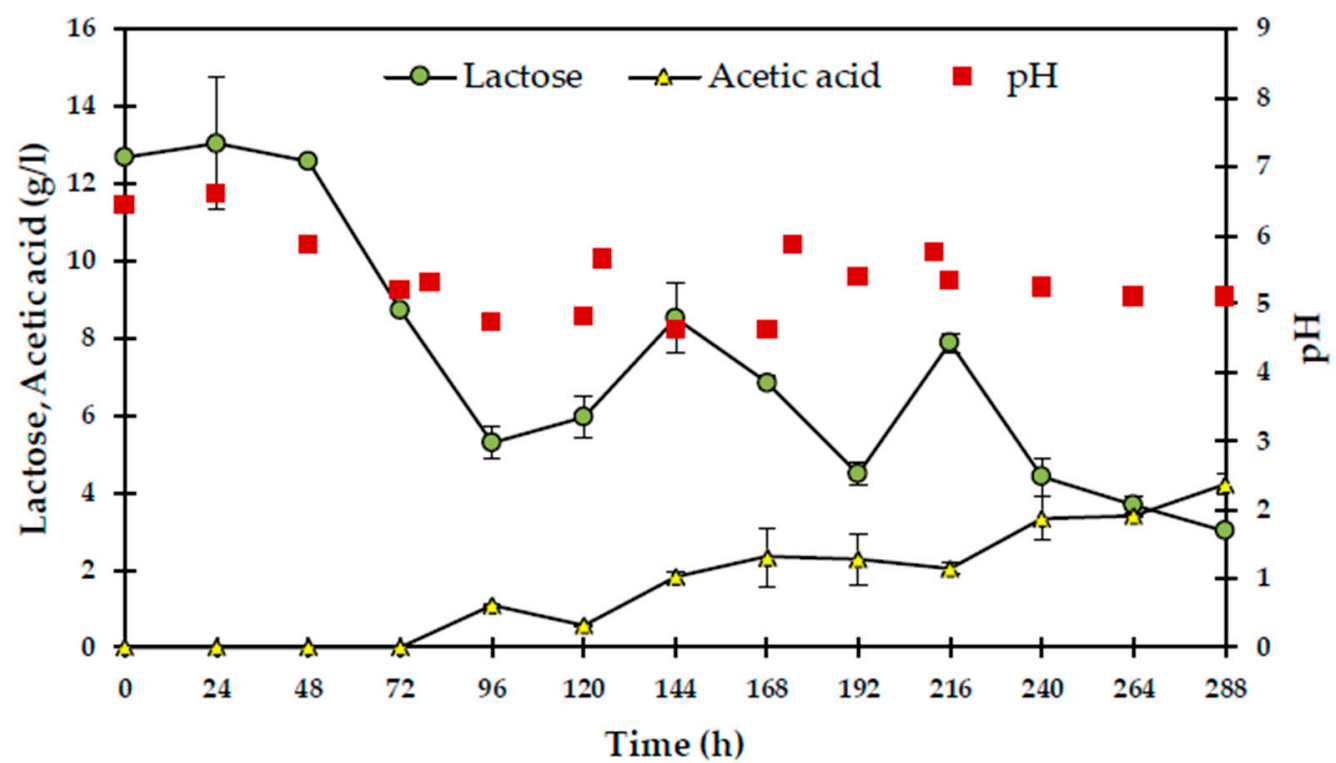

(a)

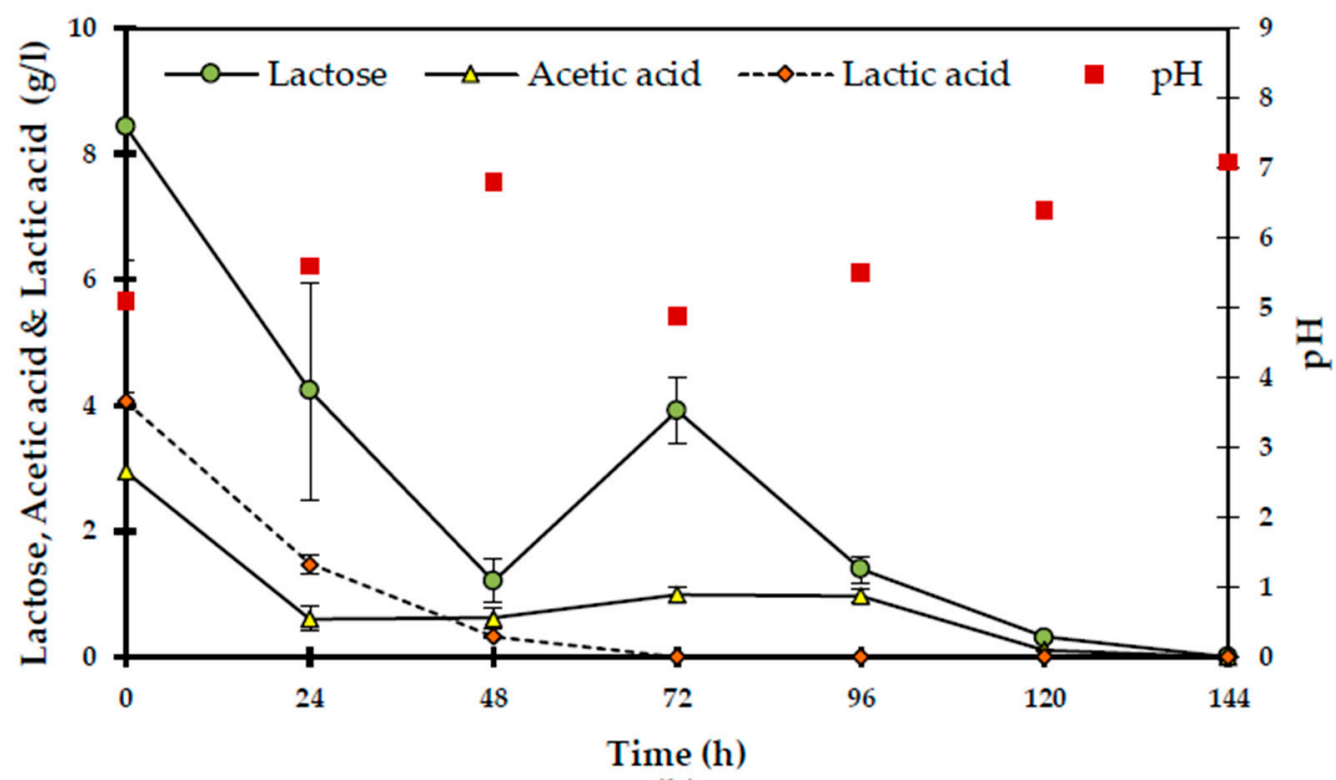

(b)

Figure 7. Profiles of substrates and metabolites during double-stage iMBR integrated cultivation of (a) A. oryzae and (b) N. intermedia. 
The same trend of changes in the lactose content of the medium was observed while filtration and feeding was applied from 72 to $124 \mathrm{~h}$, followed by a further decrease in lactose concentration resulting in a final biomass of ca $11 \mathrm{~g} / \mathrm{L}$. As A. oryzae has degraded compounds (proteins and lipids) problematic for filtration, the clear permeate medium is withdrawn at each stage without excessive membrane fouling and reserved in the buffer tank. The medium kept in the connecting tank for $48 \mathrm{~h}$, containing bacteria and bacterial metabolites (lactic and acetic acids), comprised the starting feed to the 2nd stage MBR. In addition to lactose, $N$. intermedia has been capable of assimilating acids fed to the culture as a result of bacterial activity in expired milk (Figure $7 \mathrm{~b}$ ). The ability of $\mathrm{N}$. intermedia to simultaneously consume lactic acid and milk lactose was observed previously in shake flask experiments and also in literature [11]. This metabolic activity was accompanied with an increase in the initial $\mathrm{pH}$ from 5.1 to 7.1 by the end of the cultivation (Figure 7b). By the end of the 2nd stage MBR cultivation $(144 \mathrm{~h})$, full conversion of the feed substrate (lactose and acids) was successfully achieved resulting in a biomass content of ca $7 \mathrm{~g} / \mathrm{L}$.

This semi-continuous process has the potential to efficiently convert expired milk to valuable fungal biomass and other metabolites while lowering the organic load of the effluent (clear permeate where $83 \%$ of the initial COD has been reduced) and corresponding environmental impact. It can be hypothesized that this process can be applied to more concentrated milk and dairy media if the duration of conversion at each stage is taken into consideration. In addition, such integration has various advantages including its continuous character that hampers the need to restart batch after batch, the possibility to produce biomass for feed, the control of bacterial dominance over the cultivation which circumvents the need of a sterilization step and no $\mathrm{pH}$ adjustment required since the bacterial metabolites are lowered through fungal activity. In order to benefit more from the highly valuable by-products of this process, by integration of an ultrafiltration unit in the general picture of a waste biorefinery, enzymes such as proteases, namely keratinase, pectin lyase, and lipases secreted by fungi throughout the process, can be isolated.

\section{Conclusions}

Membrane bioreactors were successfully employed in this work for valorization of milk. The use of membranes allowed taking advantage of dissimilar metabolic performance of two edible filamentous fungi towards production of biomass for e.g., animal feed or human food applications. The system developed has the potential to be used for fat-and protein-rich substrates normally a hurdle for filtration during wastewater purification due to membrane fouling. Via the strategy developed in this study, fouling can be surpassed via a fungal cultivation while obtaining various streams of value-added products within a concept of biorefinery.

Author Contributions: Conceptualization, R.T., A.M., J.A.F. and M.J.T.; Formal analysis, R.T., A.M. and J.A.F.; Investigation, R.T.; Methodology, R.T.; Project administration, M.J.T.; Supervision, A.M. and J.A.F.; Writing —original draft, A.M. and J.A.F.; Writing—review \& editing, M.J.T.

Funding: This research was funded by the Swedish Research Council Formas grant number FO2014/40.

Acknowledgments: The authors would like to thank the Swedish Research Council Formas and the University of Borås for the financial support.

Conflicts of Interest: The authors declare no conflict of interest.

\section{References}

1. FAO. Food Ourlook: Biannual Report on Global Food Markets; Trade and Markets Division: Rome, Italy, 2017.

2. FAO Save Food: Global Initiative on Food Loss and Waste Reduction. Available online: http://www.fao. org/save-food (accessed on 6 July 2016).

3. Németh, Á.; Kaleta, Z. Complex utilization of dairy waste (whey) in Biorefinery. WSEAS Trans. Environ. Dev. 2015, 11, 80-88. 
4. Guimarães, P.M.R.; Teixeira, J.A.; Domingues, L. Fermentation of lactose to bio-ethanol by yeasts as part of integrated solutions for the valorisation of cheese whey. Biotechnol. Adv. 2010, 28, 375-384. [CrossRef] [PubMed]

5. Pinto, G.A.; Giordano, R.L.C.; Giordano, R.C. Remote engineering for a cheese whey biorefinery: An Internet-based application for process design, economic analysis, monitoring, and control of multiple plant sites. Bioprocess Biosyst. Eng. 2009, 32, 69-78. [CrossRef] [PubMed]

6. Wang, X.; Ledgard, S.; Luo, J.; Guo, Y.; Zhao, Z.; Guo, L.; Liu, S.; Zhang, N.; Duan, X.; Ma, L. Environmental impacts and resource use of milk production on the North China Plain, based on life cycle assessment. Sci. Total Environ. 2018, 625, 486-495. [CrossRef] [PubMed]

7. Baldini, C.; Bava, L.; Zucali, M.; Guarino, M. Milk production life cycle assessment: A comparison between estimated and measured emission inventory for manure handling. Sci. Total Environ. 2018, 625, $209-219$. [CrossRef] [PubMed]

8. Gibbs, P.A. Growth of filamentous fungi in submerged culture: Problems and possible solutions. Crit. Rev. Biotechnol. 2000, 20, 17-48. [CrossRef] [PubMed]

9. Ferreira, J.A.; Mahboubi, A.; Lennartsson, P.R.; Taherzadeh, M.J. Waste biorefineries using filamentous ascomycetes fungi: Present status and future prospects. Bioresour. Technol. 2016, 215, 334-345. [CrossRef] [PubMed]

10. Mahboubi, A.; Ferreira, J.A.; Taherzadeh, M.J.; Lennartsson, P.R. Value-added products from dairy waste using edible fungi. Waste Manag. 2017, 59, 518-525. [CrossRef] [PubMed]

11. Mahboubi, A.; Ferreira, J.A.; Taherzadeh, M.J.; Lennartsson, P.R. Production of fungal biomass for feed, fatty Acids, and glycerol by Aspergillus oryzae from fat-rich dairy substrates. Fermentation 2017, 3, 48. [CrossRef]

12. Bentley, R. From miso, sake and shoyu to cosmetics: A century of science for kojic acid. Nat. Prod. Rep. 2006, 23, 1046-1062. [CrossRef] [PubMed]

13. Priatni, S.; Hartati, S.; Dewi, P.; Kardono, L.B.S.; Singgih, M.; Gusdinar, T. Fatty acid methyl ester from Neurospora intermedia N-1 isolated from Indonesian red peanut cake (oncom merah). Pak. J. Biol. Sci. 2010, 13, 731-737. [CrossRef] [PubMed]

14. Zhang, W.; Ding, L.; Jaffrin, M.Y.; Tang, B. Membrane cleaning assisted by high shear stress for restoring ultrafiltration membranes fouled by dairy wastewater. Chem. Eng. J. 2017, 325, 457-465. [CrossRef]

15. Liao, B.; Bokhary, A.; Cui, L.; Lin, H. A Review of membrane technology for integrated forest biorefinery. J. Membr. Sci. Res. 2017, 3, 120-141.

16. Carstensen, F.; Apel, A.; Wessling, M. In situ product recovery: Submerged membranes vs. external loop membranes. J. Membr. Sci. 2012, 394, 1-36. [CrossRef]

17. Ferreira, J.A.; Lennartsson, P.R.; Taherzadeh, M.J. Production of ethanol and biomass from thin stillage using food-grade Zygomycetes and Ascomycetes filamentous fungi. Energies 2014, 7, 3872-3885. [CrossRef]

18. Sues, A.; Millati, R.; Edebo, L.; Taherzadeh, M.J. Ethanol production from hexoses, pentoses, and dilute-acid hydrolyzate by Mucor indicus. FEMS Yeast Res. 2005, 5, 669-676. [CrossRef] [PubMed]

19. Seo, Y.H.; Lee, I.; Jeon, S.H.; Han, J.-I. Efficient conversion from cheese whey to lipid using Cryptococcus curvatus. Biochem. Eng. J. 2014, 90, 149-153. [CrossRef]

20. Schnürer, J.; Magnusson, J. Antifungal lactic acid bacteria as biopreservatives. Trends Food Sci. Technol. 2005, 16, 70-78. [CrossRef]

21. Gerez, C.L.; Torres, M.J.; De Valdez, G.F.; Rollán, G. Control of spoilage fungi by lactic acid bacteria. Biol. Control 2013, 64, 231-237. [CrossRef]

22. Klein, M.; Swinnen, S.; Thevelein, J.M.; Nevoigt, E. Glycerol metabolism and transport in yeast and fungi: Established knowledge and ambiguities. Environ. Microbiol. 2017, 19, 878-893. [CrossRef] [PubMed]

23. Kumar, S.; Kikon, K.; Upadhyay, A.; Kanwar, S.S.; Gupta, R. Production, purification, and characterization of lipase from thermophilic and alkaliphilic Bacillus coagulans BTS-3. Protein Exp. Purif. 2005, 41, 38-44. [CrossRef] [PubMed]

24. Hiol, A.; Jonzo, M.D.; Druet, D.; Comeau, L. Production, purification and characterization of an extracellular lipase from Mucor hiemalis f. hiemalis. Enzyme Microb. Technol. 1999, 25, 80-87. [CrossRef]

25. D'souza, N.; Mawson, A. Membrane cleaning in the dairy industry: A review. Crit. Rev. Food Sci. Nutr. 2005, 45, 125-134. [CrossRef] [PubMed]

26. Fernández García, L.; Riera Rodríguez, F.A. Microfiltration of milk with third generation ceramic membranes. Chem. Eng. Commun. 2015, 202, 1455-1462. [CrossRef] 
27. Farag, A.M.; Hassan, M.A. Purification, characterization and immobilization of a keratinase from Aspergillus oryzae. Enzyme Microb. Technol. 2004, 34, 85-93. [CrossRef]

28. Lásztity, R. Food Quality and Standards; Eolss Publishers Company Limited: Paris, France, 2005; p. 3.

29. Sandhya, C.; Sumantha, A.; Szakacs, G.; Pandey, A. Comparative evaluation of neutral protease production by Aspergillus oryzae in submerged and solid-state fermentation. Process Biochem. 2005, 40, $2689-2694$. [CrossRef] 